\title{
Pierre Gringore, CEuvres polémiques, rédigées sous le règne de Louis XII
}

\section{Michele Mastroianni}

\section{Q OpenEdition}

1 Journals

\section{Edizione digitale}

URL: https://journals.openedition.org/studifrancesi/40417

DOI: 10.4000/studifrancesi.40417

ISSN: 2421-5856

Editore

Rosenberg \& Sellier

\section{Edizione cartacea}

Data di pubblicazione: 1 juillet 2004

Paginazione: 167

ISSN: 0039-2944

\section{Notizia bibliografica digitale}

Michele Mastroianni, «Pierre Gringore, E Euvres polémiques, rédigées sous le règne de Louis XII», Studi Francesi [Online], 142 (XLVIII | I) | 2004, online dal 30 novembre 2015, consultato il 09 septembre 2021. URL: http://journals.openedition.org/studifrancesi/40417 ; DOI: https://doi.org/10.4000/studifrancesi. 40417

Questo documento è stato generato automaticamente il 9 septembre 2021.

\section{(c) 9 (i) $\Theta$}

Studi Francesi è distribuita con Licenza Creative Commons Attribuzione - Non commerciale - Non opere derivate 4.0 Internazionale. 


\title{
Pierre Gringore, Euvres polémiques, rédigées sous le règne de Louis XII
}

\author{
Michele Mastroianni
}

\section{NOTIZIA}

PIERRE GRINGORE, Cuvres polémiques, rédigées sous le règne de Louis XII, édition critique par CYNTHIA J. BROWN, Genève, Droz, 2003, pp. 376.

1 Si tratta di un primo volume che inaugura l'edizione delle opere complete di Pierre Gringore. Edizione benvenuta, dato che una parte considerevole della produzione di Gringore non ha mai usufruito di un'edizione moderna. Cynthia Brown edita criticamente, sotto il titolo di Euvres polémiques, otto composizioni poetiche che furono pubblicate da Gringore con lo scopo di sostenere l'offensiva di Luigi XII in Italia nel periodo dal 1499 al 1513, e precisamente le Lettres nouvelles de Milan (1500: 326 versi), La Piteuse Complainte de la Terre Sainte (1500-1501: 239 versi), L'Entreprise de Venise (1509: 238 versi), L'Union des Princes (1509: 287 versi), L'Espoir de Paix (1511: 360 versi), La Chasse du cerf des cerfz (1511: 260 versi), Le Jeu du Prince des Sotz et Mère Sotte (1512: 1245 versi), L'Obstination des Suysses (1512-1513: 134 versi). La Complainte de la Terre Sainte è la prima volta che è oggetto di un'edizione moderna; altri di questi testi, come l'Entreprise de Venise e l'Espoir de paix, sebbene pubblicati in epoca moderna, non sono apparsi in vere e proprie edizioni critiche; infine, tutte queste opere non sono mai state pubblicate insieme. Quest'ultimo aspetto - quello cioè di avere creato un corpus unitario - ha un notevole interesse per la storia dei rapporti italo-francesi, o meglio per la ricostruzione della considerazione che hanno suscitato gli interventi militari in Italia di Carlo VIII e di Luigi XII, sul piano della propaganda politica ma anche su quello di una valutazione «culturale» della presenza della Francia in Italia e all'inverso dell'Italia in Francia, con tutte le conseguenze che ne derivano per le vicende dell'italianismo e dell'antiitalianismo d'oltralpe. Lo scontro tra il Peuple François e il Peuple Italique è al centro delle Lettres nouvelles de Milan e del Jeu du Prince des Sotz, mentre negli altri testi si tratta più di un attacco puro e semplice ai nemici politici della Francia, primi tra tutti Giulio II e 
Venezia, e di un intervento propagandistico volto a fare accettare al popolo francese la guerra contro il papa. L'edizione di Cynthia Brown si raccomanda, oltre che per il rigore filologico, per lo studio linguistico che la precede, che ne fa uno strumento utile per lo storico della lingua. Ogni pièce, poi, è preceduta da un'introduzione che offre un riassunto critico della composizione, un inquadramento del contesto storico, uno studio delle tradizioni letterarie, un'indagine puntuale sulla versificazione, una rassegna delle edizioni cinquecentesche. Accurata la bibliografia, gli indici e il glossario. 